\title{
What Options Do We Have for Induction Therapy for Crohn's Disease?
}

\author{
Corey A. Siegel \\ Dartmouth-Hitchcock Medical Center, Lebanon, N.H., USA
}

\section{Key Words}

Crohn's disease $\cdot$ Induction $\cdot$ Remission

\begin{abstract}
The first goal of Crohn's disease treatment is to induce a response. The choice of induction therapy depends on a number of factors. First, disease severity will dictate the level of intensity of treatment. Moderate to severely active Crohn's disease needs to be treated more aggressively than mild disease. Second, it is important to consider the disease distribution, since some medications (e.g. 5-aminosalicylates, budesonide, antibiotics) are more effectively delivered to the small bowel or the colon. Third, prior medications need to be considered. A patient naïve to immunomodulators and anti-TNF agents will be managed very differently from a patient who has already failed two anti-TNF drugs. A fourth critical factor is considering the individual patient. The balance of benefits and risks will depend upon the patient's expected disease course, and how much risk they are at personally for serious adverse events related to treatment. In addition, patients' preferences for treatment need to be addressed since they will choose therapies differently based on their personal experience with symptoms, thresholds for risk taking, and fears about their disease and treatment. The basic armamentarium for induction therapy for Crohn's disease in-
\end{abstract}

cludes: 5-aminosalicylates, antibiotics, budesonide, systemic corticosteroids, thiopurines, methotrexate, and anti-TNF agents. These drugs can be used alone or combined in difference treatment algorithms to optimize therapy. The art of treating the IBD patient is in understanding the options and being able to apply an individualized regimen based upon unique patient and disease factors.

Copyright $\odot 2010$ S. Karger AG, Basel

\section{Introduction}

The first goal of treatment for patients with Crohn's disease is to induce a treatment response. Although the long-term objectives are to control inflammation, prevent complications and improve the overall quality of life, the initial choice of therapy will set the stage for the plan for maintenance of remission. There are a number of treatments for Crohn's disease that are used as induction therapy. Some medications are less effective but have very few side effects such as 5-aminosalicyate drugs (5-ASAs), while others have a high rate of treatment success but with the tradeoff of a high rate of adverse events such as systemic corticosteroids. The initial choice of therapy depends upon the severity of disease and required rapidity of action. For example, a patient who feels well but has a

Dr. Corey A. Siegel

Section of Gastroenterology and Hepatology, Dartmouth-Hitchcock Medical Center 1 Medical Center Drive

Lebanon, $\mathrm{NH} 03756$ (USA)

Tel. +1 603650 8101, Fax +1 603650 5225, E-Mail corey.a.siegel@ hitchcock.org 
high disease burden may be able to wait the necessary three or four months for immunomodulators to take effect, whereas a patient who is significantly symptomatic needs an immediate acting and effective agent. The induction agent chosen by the provider should match the nature of the disease and also the preferences of the patient based upon their perceptions of the balance of benefits and risks.

\section{Options for Induction Therapy}

The basic armamentarium for induction therapy for Crohn's disease includes: 5-ASAs, antibiotics, budesonide, systemic corticosteroids, thiopurines, methotrexate, and anti-TNF agents. These drugs can be used alone or combined in different treatment algorithms to optimize therapy. The approach to induction therapy can be categorized into three main groups: (1) corticosteriod induction, (2) steroid-free 'bridge' induction therapy to immunomodulators, and (3) anti-TNF induction.

\section{Corticosteroid Induction}

Prednisone is highly effective for inducing remission in patients with Crohn's disease. In the National Cooperative Crohn's Disease Study (NCCDS), a large randomized controlled trial from the 1970s, at the end of 15 weeks $60 \%$ of patients were in remission when treated with prednisone as compared to $30 \%$ of those in the placebo group $(\mathrm{p}<0.001)[1]$. There is not much debate about the effectiveness of corticosteroids for improving symptoms, but once initiated, the long-term outcomes are disappointing. In a cohort of patients from Olmsted County (Minn., USA) although over $80 \%$ of patients had either a complete or partial response to corticosteroids at 30 days, at the end of one year, only $28 \%$ had a prolonged response, $32 \%$ were steroid dependent, and $38 \%$ required surgery [2]. Even if patients respond, adverse effects are common. Approximately $50 \%$ of patients receiving corticosteroids stop taking this medication due to some side effect. Common events that are typically quickly reversible upon cessation of therapy include acne, moon facies, easy bruising, and ankle edema. More serious long-term problems related to steroid use include osteoporosis, cataracts and diabetes [3, 4]. Furthermore, in a recent population based study including almost 6,000 patients from the United Kingdom, the highest risk of death were in those patients treated with corticosteroids (HR 2.48, 95\% CI 1.85-3.31). Although 'bias by indication' might be in part responsible (e.g. sicker patients received corticosteroids), the hazard ratio of those receiving thiopurines was 0.83 , and although not statistically significant to be protective it strengthens the argument of a detrimental effect of corticosteroids.

\section{Prednisone-Free 'Bridge' Induction to Immunomodulators}

Patients with Crohn's disease who have more than mildly active disease typically will receive immunomodulators (azathioprine, 6-mercaptopurine, methotrexate) to maintain remission. Since there is a delay of onset of the effectiveness of these medications of approximately 2-4 months, some treatment is required to help induce remission while awaiting their effects. Although corticosteroids can be used to bridge this gap, as noted above, if possible, it is optimal to avoid systemic corticosteroid exposure.

Sulfasalazine was also studied in the NCCDS and compared to placebo for effectiveness in inducing remission [1]. At a dose of $1 \mathrm{~g} / 15 \mathrm{~kg}$, at week fifteen $43 \%$ of patients receiving sulfasalazine were in remission compared to $30 \%$ of those in the placebo group ( $p=0.08$ ). Although this just missed statistical significance, the authors noted that for the subgroup of patients with colonic disease, sulfasalazine appeared to be particularly effective. The other 5-ASA derivatives may not be as effective in Crohn's disease. Although one study showed mesalamine capsules (Pentasa) were effective for the treatment of active Crohn's disease [5], when this was combined with two other studies as part of a meta-analysis, the overall response was far from overwhelming [6]. At 16 weeks, although the mean reduction of the Crohn's Disease Activity Index (CDAI) was 63 points in the treatment group, the placebo group dropped 45 points. The comparison between groups was statistically significant ( $\mathrm{p}=0.04$ ), but the difference of 18 CDAI points is considered not clinically important, and therefore has led to the abandonment of mesalamine for the treatment of Crohn's disease by many experts.

Budesonide is a corticosteroid with minimal absorption and therefore minimal systemic exposure. Based on its $\mathrm{pH}$ sensitive coating, this medication is delivered primarily to the ileum and right colon. With a side effect profile that is better than systemically absorbed corticosteroids, this is an appealing drug for the induction of remission of Crohn's disease. In a randomized controlled trial using budesonide at a daily dose of either 3, 9 or $15 \mathrm{mg}$, all compared to placebo, the $9 \mathrm{mg}$ dose was superior at weeks 2 and 8 [7]. The rate of remission at two weeks was $33 \%$ in the budesonide group (compared to 
$11 \%$ for placebo) and $51 \%$ at week 8 (compared to $21 \%$ for placebo, $\mathrm{p}<0.001)$. A study published in the same issue of the New England Journal of Medicine in 1994 compared budesonide to prednisolone for the induction of remission of Crohn's disease [3]. There was a small absolute difference in the remission rate between these two drugs at 10 weeks ( $53 \%$ budesonide group, $66 \%$ prednisolone group), but this was not statistically significant ( $\mathrm{p}=$ 0.12 ). However, there was a significant difference in the frequency of side effects favoring budesonide $(p=0.003)$, suggesting that budesonide is nearly as effective as prednisolone but better tolerated.

Antibiotics have been studied for the treatment of Crohn's disease for years, but there is still uncertainty about their effectiveness. Sutherland et al. published a randomized controlled trial comparing metronidazole to placebo in patients with active Crohn's disease [8]. There was no difference in remission rates between the two groups, but there was a significant difference for improvement in the CDAI $(\mathrm{p}=0.001)$. In a subgroup analysis of the data, it appears that this difference comes predominantly from the patients with colonic involvement, as there was not a difference seen in those with isolated small bowel disease. More recently rifaximin, a non-absorbable antibiotic, was evaluated in patients with active Crohn's disease [9]. At week 12 more patients in the rifaximin group responded to treatment. Although this did not reach statistical significance, the subgroup of patients with an elevated C-reactive protein who received rifaximin $800 \mathrm{mg}$ twice daily did have significantly higher rates of remission and response as compared to placebo $(\mathrm{p}<0.05)$.

In an effort to optimize the use of budesonide and antibiotics, Steinhart et al. evaluated the efficacy of budesonide on its own as compared to budesonide in combination with antibiotics (ciprofloxacin and metronidazole) [10]. There was no difference in remission rates at week 8 between the two groups. In a sub-group analysis of patients with colonic disease, although still not statistically significant $(\mathrm{p}=0.10)$, there was a fairly large absolute difference in remission rates $(53 \%$ with budesonide and antibiotics, 25\% with budesonide alone). The small sample size of this sub-group limits the clear interpretation of these results, but intuitively the addition of antibiotics to budesonide in patients with Crohn's disease involving the ileum and colon may add some incremental benefit. Overall, there is no clear benefit of antibiotics for the treatment of Crohn's disease; however, there likely are subgroups of patients who will respond to these medications.

\section{Anti-TNF Induction}

Anti-TNF therapy offers a rapid onset of efficacy, which makes this class of medication an appealing induction agent while also allowing for the avoidance of corticosteroids. In the large registration trials for adalimumab, certolizumab pegol, and infliximab, the rate of responding to an induction regimen within the first few weeks of therapy is approximately equivalent across agents at about $60 \%$ [11-13]. Although not quite as high as the response rate of corticosteroids, these agents typically are well tolerated and are more effective than other treatments for inducing response or remission in patients with Crohn's disease. With that said, $40 \%$ of patients do not respond, which leaves a significant amount of room for improvement.

There have been a few strategies sought to improve the response rate of anti-TNF agents. First, the use of infliximab has been studied in a 'top-down' approach, by giving infliximab in combination with azathioprine to patients naïve to these medications and before using corticosteroids [14]. This top-down strategy yielded a $65 \%$ remission rate at week 14 compared to $30 \%$ in the standard 'step-up' approach of waiting to administer antiTNF agents until patients have failed steroid withdrawal and immunomodulators. The SONIC trial further explored the question of the early use of anti-TNF medications and additionally studied the benefit of the combination of anti-TNF and immunomodulator therapy versus anti-TNF monotherapy [15]. Although the primary endpoint of the trial regarded maintenance of remission at week 26 , even by 10 weeks there started to be a separation of the groups, with combination therapy showing superiority. One other important study approached this same question from a slightly different angle. The COMMIT study compared anti-TNF monotherapy to anti-TNF therapy combined with methotrexate [16]. All of these patients were also given prednisone for the induction period. Therefore, we see the results of 'triple-drug therapy' with an anti-TNF, immunomodulator and corticosteroids used concomitantly. In COMMIT, we see the highest rates of remission in any randomized controlled trial for Crohn's disease, with nearly $80 \%$ of patients in steroid-free clinical remission at week 14 . From these series of studies, we learn that anti-TNF therapy is very effective for the induction of a treatment response and remission, and that adding an immunomodulator, and possibly prednisone, further enhances the rates of success. 
Table 1. Options for Crohn's disease induction therapy

\begin{tabular}{ll}
\hline Mild endoscopic disease & Moderate-severe endoscopic disease \\
\hline $\begin{array}{l}\text { Minimal symptoms } \\
\text { Budesonide for ileal disease and/or }\end{array}$ & $\begin{array}{l}\text { Minimal symptoms ('rapid step-up') } \\
\text { antibiotics for colonic disease or }\end{array}$ \\
sulfasalazine for colonic disease & $\begin{array}{l}\text { budesonide for ileal disease and/or } \\
\text { antibiotics for colonic disease }\end{array}$ \\
\hline Moderate to significant symptoms & Moderate to significant symptoms \\
Systemic corticosteroids & Systemic corticosteroids plus IM or \\
& Anti-TNF +/- IM or \\
& Anti-TNF + IM + corticosteroids \\
\hline
\end{tabular}

$\mathrm{IM}=\mathrm{Immunomodulator}$

\section{Conclusions}

There are a number of agents that can be used with success to induce a treatment response and remission for patients with active Crohn's disease. As reviewed above, some agents have more supportive data than others, and some are clearly more effective with or without the risk of added adverse events. The decision to use a particular agent or agents is based upon the individual patient. Clear algorithms that apply to all patients are difficult to produce based upon the numerous combinations of patient and disease variables. A recent RAND expert panel made recommendations on the use of anti-TNF agents with or without immunomodulators for the treatment of active Crohn's disease. To capture the different types of patients we treat in clinical practice, the panel developed 134 different patient scenarios [17]. Therefore, in addition to having to know the available induction treatment options, individualize choices have to be made based on the severity of their disease and current symptoms (table 1). Patients with mildly active endoscopic disease who are only minimally symptomatic have time to try medications that are safe which may or may not be effective. Patients with mild endoscopic disease but who are more bothered by symptoms can be treated with systemic corticosteroids with a high likelihood of treatment success. Patients with moderate to severely active endoscopic disease who are minimally symptomatic also have time to try induction therapy without the use of systemic corticosteroids or anti-TNF agents while awaiting the effects of immunomodulators. However, they should have a 'rapid step-up' approach, with a swift move to systemic corticosteroids or an anti-TNF agent if they are not quickly obtaining remission and mucosal healing. Patients with moderate to severely active endoscopic disease who are more symptomatic should be treated with either antiTNF monotherapy, combination therapy with an antiTNF agent and an immunomodulator, or 'triple-drug' therapy adding systemic corticosteroids. These choices should be made together with patients, weighing the benefits against the risks, so that a shared decision can be made to best treat the individual patient.

\section{Acknowledgements}

Dr. Siegel is supported by a CCFA career development award and by grant No. K23DK078678 from the National Institute of Diabetes and Digestive and Kidney Diseases. The content is solely the responsibility of the author and does not necessarily represent the official views of the National Institute of Diabetes and Digestive and Kidney Diseases or the National Institutes of Health.

\section{Disclosure Statement}

Dr. Siegel has served as a consultant and developed and delivered CME material for Abbott Labs, Elan Pharmaceuticals, and UCB. He has also served on the advisory board for P\&G/Warner Chilcott.

References

Summers RW, Switz DM, Sessions JT Jr, Becktel JM, Best WR, Kern F Jr, et al: National Cooperative Crohn's Disease Study: results of drug treatment. Gastroenterology 1979;77:847-869.

\2 Faubion WA Jr, Loftus EV Jr, Harmsen WS, Zinsmeister AR, Sandborn WJ: The natural history of corticosteroid therapy for inflammatory bowel disease: a population-based study. Gastroenterology 2001;121:255-260. 
3 Rutgeerts P, Lofberg R, Malchow H, Lamers C, Olaison G, Jewell D, et al: A comparison of budesonide with prednisolone for active Crohn's disease. N Engl J Med 1994;331:842845.

4 Rutgeerts PJ: Review article: the limitations of corticosteroid therapy in Crohn's disease. Aliment Pharmacol Ther 2001;15:15151525.

5 Singleton JW, Hanauer SB, Gitnick GL, Peppercorn MA, Robinson MG, Wruble LD, et al: Mesalamine capsules for the treatment of active Crohn's disease: results of a 16-week trial. Pentasa Crohn's Disease Study Group. Gastroenterology 1993;104:1293-1301.

6 Hanauer SB, Stromberg U: Oral Pentasa in the treatment of active Crohn's disease: a meta-analysis of double-blind, placebo-controlled trials. Clin Gastroenterol Hepatol 2004;2:379-388.

7 Greenberg GR, Feagan BG, Martin F, Sutherland LR, Thomson AB, Williams $\mathrm{CN}$, et al: Oral budesonide for active Crohn's disease. Canadian Inflammatory Bowel Disease Study Group. N Engl J Med 1994;331:836841 .
$>8$ Sutherland L, Singleton J, Sessions J, Hanauer S, Krawitt E, Rankin G, et al: Double blind, placebo controlled trial of metronidazole in Crohn's disease. Gut 1991;32:1071-1075.

-9 Prantera C, Lochs H, Campieri M, Scribano ML, Sturniolo GC, Castiglione F, et al: Antibiotic treatment of Crohn's disease: results of a multicentre, double blind, randomized, placebo-controlled trial with rifaximin. Aliment Pharmacol Ther 2006;23:1117-1125.

10 Steinhart AH, Feagan BG, Wong CJ, Vandervoort M, Mikolainis S, Croitoru K, et al: Combined budesonide and antibiotic therapy for active Crohn's disease: a randomized controlled trial. Gastroenterology 2002;123: 33-40.

$\checkmark 11$ Colombel JF, Sandborn WJ, Rutgeerts P, Enns R, Hanauer SB, Panaccione R, et al: Adalimumab for maintenance of clinical response and remission in patients with Crohn's disease: the CHARM trial. Gastroenterology 2007;132:52-65.

12 Hanauer SB, Feagan BG, Lichtenstein GR, Mayer LF, Schreiber S, Colombel JF, et al: Maintenance infliximab for Crohn's disease: the ACCENT I randomised trial. Lancet 2002;359:1541-1549.
13 Sandborn WJ, Feagan BG, Stoinov S, Honiball PJ, Rutgeerts P, Mason D, et al: Certolizumab pegol for the treatment of Crohn's disease. N Engl J Med 2007;357:228-238.

14 D'Haens G, Baert F, van Assche G, Caenepeel P, Vergauwe P, Tuynman H, et al: Early combined immunosuppression or conventional management in patients with newly diagnosed Crohn's disease: an open randomised trial. Lancet 2008;371:660-667.

15 Colombel JF, Sandborn WJ, Reinisch W, Mantzaris GJ, Kornbluth A, Rachmilewitz $\mathrm{D}$, et al: Infliximab, azathioprine, or combination therapy for Crohn's disease. N Engl J Med 2010;362:1383-1395.

16 Feagan BG, et al: Combination of maintenance methotrexate-infliximab trial (COMMIT). Presented at: Digestive Disease Week, May 2008, abstract 682C.

17 Melmed GY, Spiegel BM, Bressler B, Cheifetz AS, Devlin SM, Harrell LE, et al: The appropriateness of concomitant immunomodulators and anti-TNF agents for Crohn's disease: One size does not fit all. Clin Gastroenterol Hepatol 2010, E-pub ahead of print. 